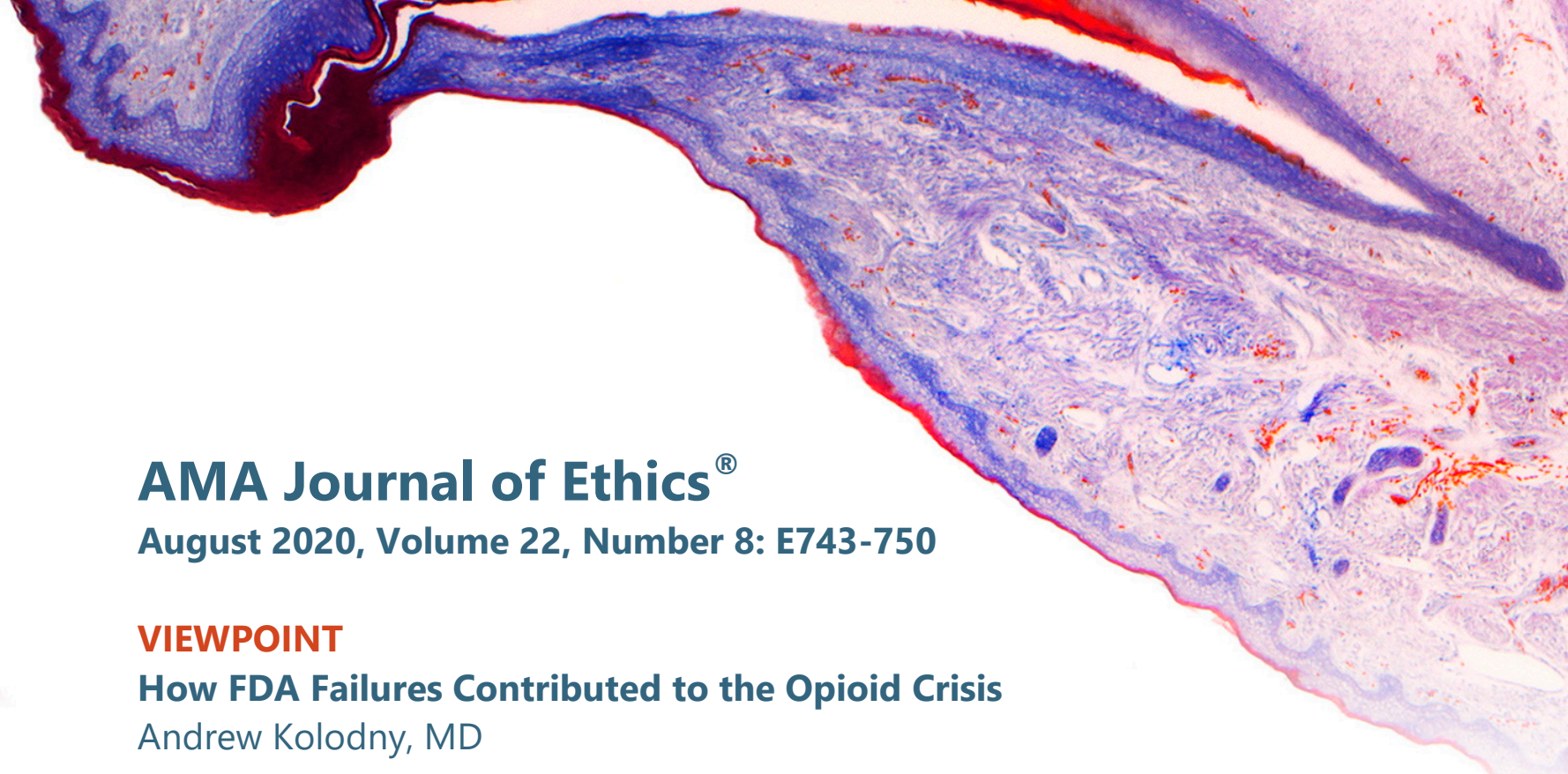

\begin{abstract}
Over the past 25 years, pharmaceutical companies deceptively promoted opioid use in ways that were often neither safe nor effective, contributing to unprecedented increases in prescribing, opioid use disorder, and deaths by overdose. This article explores regulatory mistakes made by the US Food and Drug Administration (FDA) in approving and labeling new analgesics. By understanding and correcting these mistakes, future public health crises caused by improper pharmaceutical marketing might be prevented.
\end{abstract}

\title{
Introduction
}

In the United States, opioid use disorder (OUD) and opioid overdose were once rare. But over the past 25 years, the number of Americans suffering from OUD increased exponentially and in parallel with an unprecedented increase in opioid prescribing. ${ }^{1}$ Today, OUD is common, especially in patients with chronic pain treated with opioid analgesics, ${ }^{1}$ and opioid overdose is the leading cause of accidental death. ${ }^{2}$

The high prevalence of OUD has led to an array of health and social problems. The United States has seen record high rates of neonatal opioid withdrawal syndrome, more children entering foster care ${ }^{3}$ rising heroin and fentanyl use, ${ }^{4}$ outbreaks of injectionrelated infectious diseases, ${ }^{5}$ and a decline in workforce participation in areas with relatively high rates of opioid prescribing. ${ }^{6}$ The Centers for Disease Control and Prevention (CDC) has aptly described the crisis as the "worst drug overdose epidemic in [US] history."1

Using the term epidemic to describe the sharp increase in OUD and overdose deaths is appropriate. But we should recognize that, unlike communicable disease outbreaks, the opioid crisis was not caused by a pathogen. As a federal judge presiding over hundreds of county and state cases against opioid manufacturers and distributors recently found: "It is accurate to describe the opioid epidemic as a man-made plague, 20 years in the making." 7

Much of the responsibility for the opioid crisis rests with the pharmaceutical industry's promotion of aggressive opioid prescribing. Indeed, in a first-of-its-kind trial against opioid manufacturers, a state court in Oklahoma last year found that the "exponentially 
increasing rates of addiction," "overdose deaths," and babies born exposed to opioids were caused by "false, misleading, and dangerous marketing campaigns" for opioid medications. ${ }^{8}$ But the fact that opioid manufacturers disseminated false claims regarding the risks and benefits of opioids for the past 25 years points to a dereliction of duty by the US Food and Drug Administration (FDA)-the federal agency charged with regulating pharmaceutical companies.

\section{Regulatory Failures}

The FDA's regulatory failures with respect to opioids have not gone unnoticed. In 2017, the President's Commission on Combatting Drug Addiction and the Opioid Crisis found that the opioid crisis was caused in part by "inadequate oversight by the Food and Drug Administration," and the National Academy of Sciences (NAS) publicly called on the FDA to overhaul its opioid policies.9,10 Last year, a former FDA Commissioner rebuked the agency he had previously led, saying on the television program 60 Minutes that the FDA was wrong to allow promotion of opioid use for chronic pain. ${ }^{11}$

Despite this mounting criticism, FDA policies for approving and labeling opioids remain largely unchanged. The FDA has not undertaken a root cause analysis of its regulatory errors that contributed to this public health catastrophe, let alone instituted any major reforms. ${ }^{11}$ To the contrary, the agency has adopted a defensive posture and sought to shift blame. For example, in response to a critical letter from Senator Maggie Hassan of New Hampshire, the FDA's top official at the Center for Drug Evaluation and Research since 1994 offered a blanket defense of the FDA's handling of opioids, claiming that the agency has properly enforced the Food, Drug, and Cosmetic Act.12

This article does not attempt to provide a full accounting of the FDA's role in the opioid crisis. Nor is such an accounting possible without full participation of the FDA and its official oversight bodies. Rather, this article focuses on just a few policy failures that contributed to the opioid crisis. Until these past mistakes are understood and corrected, the United States will remain vulnerable to health crises caused by inadequate regulation of pharmaceutical companies. In the following discussion, I detail FDA failures to regulate false marketing claims by opioid manufacturers and to require adequate and well-controlled clinical trials for opioids and its poor management of conflicts of interest between FDA staff and industry. Understanding how and why the FDA allowed improper marketing of opioids can help us better address the current crisis and improve regulation of pharmaceutical companies in the future.

\section{Failure to Properly Enforce Marketing Regulations}

The Food, Drug, and Cosmetic Act requires drug manufacturers to demonstrate that their products are both safe and effective before they are marketed.13 The benefits of a drug must outweigh potential risks for specific indications listed on an FDA-approved label. ${ }^{13}$ Although prescribing medication for unapproved uses is common and sometimes appropriate, drug makers are prohibited from promoting off-label uses without premarket review by the FDA. ${ }^{13}$

The FDA did not properly enforce the Food, Drug, and Cosmetic Act when it approved Purdue Pharma's new drug application for extended-release (ER) oxycodone in 1995. Had it done so, ER oxycodone's label would have had a narrow indication for the specific conditions for which the benefits of ER oxycodone outweigh the risks, such as relief from severe pain from a life-limiting illness. Instead, the label on ER oxycodone featured a 
broad indication, ${ }^{14}$ allowing Purdue to promote the drug's use for common conditions for which opioids are more likely to harm than help, such as low-back pain and fibromyalgia.

As Purdue earned billions of dollars from sales of oxycodone, other drug companies took note. ${ }^{15}$ They introduced their own opioids and joined Purdue in funding a brilliant, multifaceted campaign that changed the culture of opioid prescribing in the United States. Clinicians who previously understood that opioids are addictive, that development of tolerance results in dose escalation, and that dependence would make discontinuation difficult began hearing from spokesmen for opioid manufacturers that addiction was rare and that long-term use was safe and effective. $1,6,7,8,9,10,11,12,13,15$ Risks were minimized, benefits were exaggerated, and opioid prescribing surged.

In 2002, faced with evidence that opioid prescribing had risen beyond levels that could be clinically warranted, the FDA convened an advisory committee meeting of 10 outside experts and asked if the broad indication on opioid labels should be narrowed to prohibit marketing for common chronic pain conditions. ${ }^{16}$ Eight of these experts had financial ties to pharmaceutical companies, including Purdue, 16 and advised the FDA against narrowing the indication. ${ }^{17}$ An opportunity to reign in overprescribing early in the crisis was lost, and, by 2013 , enough opioids were prescribed to provide every adult in the country with a full pill bottle. 18

\section{Failure to Obtain Evidence of Long-term Safety and Effectiveness}

Marketing opioids as safe for long-term use is at odds with a growing body of medical literature, dating from the 1950s, 19 which demonstrates serious dose-dependent risks, including addiction, respiratory depression, neuroendocrine dysfunction, and other medical problems. ${ }^{20}$ Even in safety trials for opioid drugs approved by the FDA, serious adverse events-including respiratory depression, death, and drug diversion-are common. ${ }^{21,22}$ And, despite evidence that as many as $41 \%$ of patients on long-term opioids meet the Diagnostic and Statistical Manual of Mental Disorders fifth edition (DSM-5) criteria for OUD, 23 drug companies are not required to assess clinical trial subjects for development of OUD at the conclusion of a study.

The Food, Drug, and Cosmetic Act requires "adequate and well-controlled studies" before products can be approved and promoted as safe and effective. ${ }^{13}$ The FDA generally requires at least 2 randomized controlled trials demonstrating clear efficacy for a proposed indication. ${ }^{24}$ Yet it approved extended release oxycodone based on only one adequate and well-controlled study, a 2-week clinical trial in osteoarthritis patients. ${ }^{25}$

FDA failure to obtain adequate evidence of effectiveness was not limited to oxycodone. Over the past 25 years, despite mounting evidence that a surge in opioid consumption was resulting in adverse public health consequences, the FDA continued to approve new opioid formulations for chronic pain based on efficacy trials utilizing a controversial methodology called enriched enrollment randomized withdrawal (EERW). ${ }^{26}$ Since its 2006 approval of oxymorphone, the FDA has relied on EERW as evidence of opioid efficacy for chronic pain. ${ }^{27}$ EERW trials differ from traditional double-blind, randomized, controlled studies. In an EERW trial, prior to randomization for a double-blind phase, all subjects are made physiologically dependent on the opioid in a 4- to 6-week open-label phase. Then only the patients who tolerated the opioid and found it helpful during the open-label phase are randomized to remain on the opioid or switch to a placebo. 
Critics of EERW have correctly described this methodology as "cooking the books" for 2 reasons. ${ }^{28}$ First, because only patients who tolerated the opioid and found it helpful are allowed to proceed to randomization, the study is not representative of the general population, and the results cannot be generalized to clinical practice. Second, because daily use of opioids causes physiological dependence, efficacy results are skewed in favor of the subjects who remain on the opioid. This is because opioid-dependent subjects who are switched to placebo experience opioid withdrawal symptoms, including increased sensitivity to pain. Moreover, switching opioid-dependent subjects to placebo renders the study not truly double-blind.

The FDA's decision to rely on EERW trial methodology is a consequence of the agency's close ties to industry. In fact, the FDA's decision to use EERW for analgesics was based on discussions at private meetings between FDA officials and pharmaceutical company executives hosted by an organization called Initiative on Methods, Measurement, and Pain Assessment in Clinical Trials (IMMPACT). ${ }^{29}$ Drug companies paid up to $\$ 35000$ each for the opportunity to attend IMMPACT meetings and interact with FDA staff. ${ }^{29}$ Yet, despite the uproar that followed public disclosure of the IMMPACT meetings, the FDA continues to rely on EERW trials as evidence that opioids are effective for chronic pain. ${ }^{26}$

\section{Failure to Manage Conflicts of Interest}

The FDA has never been held to account for its improper handling of the opioid crisis. But the FDA's conduct is all the more troubling in light of the close relationship between the agency officials responsible for opioid oversight and opioid manufacturers. For example, the 2 principal FDA reviewers who originally approved Purdue's oxycodone application both took positions at Purdue after leaving the agency. ${ }^{11}$ Over the past 20 years, several other FDA staff involved in opioid approvals also left the FDA to work for opioid makers. Last January, the head of the FDA's analgesic division retired from the FDA to start her own consulting business, which promises drug makers "help" to "successfully and efficiently bring your products to market" with "more than 30 years of experience at the FDA." 30 To be clear, the revolving door between the FDA and the pharmaceutical industry is not limited to opioids. A 2018 study found that 11 of 16 FDA medical reviewers involved in approving 28 products now work for the companies whose products they regulated. ${ }^{31}$ Without appropriate limits on employment after leaving the FDA, staff might be tempted to put the interests of future employers, whose favor they wish to gain, ahead of public health.

\section{Oversight Recommendations}

While fewer clinicians are initiating long-term opioids, overprescribing is still a problem. According to a recently published report, more than 2.9 million people initiated opioid use in December 2017.32 The FDA's continued approval of new opioids exacerbates this problem. Each time a branded opioid hits the market, the company, eager for return on its investment, is given an incentive and, in essence, a license to promote aggressive prescribing. The FDA's continued approval of new opioids pits the financial interests of drug companies against city, state, and federal efforts to discourage initiation of longterm opioids.

To finally end the opioid crisis, the FDA must enforce the Food, Drug, and Cosmetic Act, and it must act on recommendations from the NAS for an overhaul of its opioid approval and removal policies. The broad indication on opioid labels must be narrowed, and an explicit warning against long-term use and high-dose prescribing should be added. The label should reinforce, rather than contradict, guidance from the CDC, the Department 
of Veterans Affairs, the Agency for Healthcare Research and Quality, and other public health agencies that are calling for more cautious prescribing. ${ }^{18,33,34}$

Oversight bodies within the Executive Branch and Congress should conduct a longoverdue examination of the FDA's role in the opioid crisis. Past mistakes must be corrected, and preventative measures, such as rules to stop the revolving door, must be put in place to ensure that public health is consistently prioritized ahead of industry interests. Understanding why our regulatory systems failed to prevent a man-made epidemic is a critical step toward abating the opioid crisis and preventing future public health catastrophes.

\section{References}

1. Kolodny A, Courtwright DT, Hwang CS, et al. The prescription opioid and heroin crisis: a public health approach to an epidemic of addiction. Annu Rev Public Health. 2015;36(1):559-574.

2. National Safety Council Injury Facts ${ }^{\circledR}$. Preventable deaths: odds of dying. https://injuryfacts.nsc.org/all-injuries/preventable-death-overview/odds-ofdying/data-details/. Accessed May 29, 2020.

3. Lynch S, Sherman L, Snyder SM, Mattson M. Trends in infants reported to child welfare with neonatal abstinence syndrome (NAS). Child Youth Serv Rev. 2018;86(C):135-141.

4. O'Donnell JK, Gladden RM, Seth P. Trends in deaths involving heroin and synthetic opioids excluding methadone, and law enforcement drug product reports, by census region-United States, 2006-2015. MMWR Morb Mortal Wkly Rep. 2017;66(34):897-903.

5. Paquette CE, Pollini RA. Injection drug use, HIV/HCV, and related services in nonurban areas of the United States: a systematic review. Drug Alcohol Depend. 2018;188:239-250.

6. Krueger $A B$. Where have all the workers gone? An inquiry into the decline of the US labor force participation rate. Brookings Papers on Economic Activity Conference draft. https://www. brookings.edu/wpcontent/uploads/2017/09/1_krueger.pdf. Published August 26, 2017. Accessed April 21, 2020.

7. Feeley J. Opioid-industry claims proceed as judge cites "man-made plague." Bloomberg News. December 20, 2018. https://www.bloomberg.com/news/articles/2018-12-20/opioid-industry-claimsproceed-as-judge-cites-man-made-plague. Accessed January 16, 2020.

8. Hoffman J. Johnson \& Johnson ordered to pay $\$ 572$ million in landmark opioid trial. New York Times. August 26, 2019.

https://www.nytimes.com/2019/08/26/health/oklahoma-opioids-johnson-andjohnson.html. Updated August 30, 2019. Accessed on January 16, 2020.

9. Christie C, Baker C, Cooper R, Kennedy PJ, Madras B, Bondi P. The President's Commission on combating drug addiction and the opioid crisis.

https://www.whitehouse.gov/sites/whitehouse.gov/files/images/Final_Report_ Draft_11-1-2017.pdf. Published November 1, 2017. Accessed January 16, 2020.

10. Bonnie RJ, Kesselheim AS, Clark DJ. Both urgency and balance needed in addressing opioid epidemic: a report from the National Academies of Sciences, Engineering, and Medicine. JAMA. 2017;318(5):423-424.

11. Whitaker B. Did the FDA Ignite the Opioid Crisis? [video]. 60 Minutes. CBS television. https://www.cbsnews.com/video/opioid-epidemic-did-the-fda-ignite- 
the-crisis-60-minutes/. Published February 24, 2019. Accessed February 18, 2020.

12. Woodcock J; US Food and Drug Administration. Letter to Senator Margaret Hassan, United States Congress. January 21, 2020.

13. Hamburg MA. Shattuck lecture. Innovation, regulation, and the FDA. $N$ Engl J Med. 2010;363(23):2228-2232.

14. Purdue Pharma. Purdue Pharma statement to 60 Minutes regarding the segment on opioid medicines expected to air Sunday, February 24, 2019. https://www.purduepharma.com/news/2019/02/22/purdue-pharmastatement-to-60-minutes-regarding-the-segment-on-opioid-medicines-expectedto-air-sunday-february-24-2019/. Published February 22, 2019. Accessed May 22, 2020.

15. US General Accounting Office. Prescription drugs: OxyContin abuse and diversion and efforts to address the problem.

http://www.gao.gov/new. items/d04110.pdf. Published December 2003. Accessed April 27, 2020.

16. Whoriskey P. Rising painkiller addiction shows damage from drugmakers' role in shaping medical opinion. Washington Post. December 30, 2012. https://www.washingtonpost.com/business/economy/2012/12/30/014205a6 -4bc3-11e2-b709-667035ff9029_story.html. Accessed June 9, 2020.

17. Center for Drug Evaluation and Research, US Food and Drug Administration. Meeting of the Anesthetic and Life Support Drugs Advisory Committee, January 30, 2002; Gaithersburg, MD.

18. Centers for Disease Control and Prevention. CDC guideline for prescribing opioids for chronic pain. https://www.cdc.gov/drugoverdose/pdf/guidelines_ata-glance-a.pdf. Accessed February 18, 2020.

19. Rayport M. Experience in the management of patients medically addicted to narcotics. JAMA. 1954;156(7):684-691.

20. Chou R, Turner JA, Devine EB, et al. The effectiveness and risks of long-term opioid therapy for chronic pain: a systematic review for a National Institutes of Health Pathways to Prevention Workshop. Ann Intern Med. 2015;162(4):276286.

21. Kornfeld M. The Health 202: Patients overdosed on opioids in a clinical trial. Now Virginia is suing. Washington Post. February 10, 2020. https://www.washingtonpost.com/news/powerpost/paloma/the-health202/2020/02/10/the-health-202-patients-overdosed-on-opioids-in-a-clinicaltrial-now-virginia-is-suing/5e3e1fc288eOfa0a47d9c6a3/. Accessed April 27, 2020.

22. Rabin RC. New painkiller rekindles addiction concerns. New York Times. April 21, 2014. https://well.blogs.nytimes.com/2014/04/21/new-painkiller-rekindlesaddiction-concerns/. Accessed on April 20, 2020.

23. Boscarino JA, Hoffman SN, Han JJ. Opioid-use disorder among patients on longterm opioid therapy: impact of final $D S M-5$ diagnostic criteria on prevalence and correlates. Subst Abuse Rehabil. 2015;6:83-91.

24. Downing NS, Aminawung JA, Shah ND, Krumholz HM, Ross JS. Clinical trial evidence supporting FDA approval of novel therapeutic agents, 2005-2012. JAMA. 2014;311(4):368-377.

25. Purdue Pharma. Application summary: oxycodone hydrochloride controlled release tablets (OxyContinTM tablets). December 6, 1995.

26. Campbell J, King NB. "Unsettling circularity": clinical trial enrichment and the evidentiary politics of chronic pain. BioSocieties. 2017;12:191-216. 
27. McGreal C. American Overdose: The Opioid Tragedy in Three Acts. New York, NY: Public Affairs; 2018.

28. Hassan MW, Markey EJ. Letter to FDA Commissioner Scott Gottlieb. March 27, 2019.

https://www.hassan.senate.gov/imo/media/doc/Hassan\%20Letter\%20to\%20F DA.pdf. Accessed April 27, 2020.

29. Fauber J. FDA and pharma: emails raise pay-for-play concerns. MedPage Today. October 7, 2013.

https://www.medpagetoday.com/painmanagement/painmanagement/42103. Accessed February 20, 2020.

30. Sharon Hertz LinkedIn page. https://www.linkedin.com/in/sharon-hertz$7 \mathrm{bb} 28 \mathrm{a30}$. Accessed February 20, 2020.

31. Piller C. Is FDA's revolving door open too wide? Science. 2018;361(6397):21.

32. Bresnick J. Opioid prescriptions dropped $12 \%$ in 2017 as guidelines change. HealthITAnalytics. April 23, 2018. https://healthitanalytics.com/news/opioidprescriptions-dropped-12-in-2017-as-guidelines-change. Accessed June 10, 2019,

33. Rosenberg JM, Bilka BM, Wilson SM, Spevak C. Opioid therapy for chronic pain: overview of the 2017 US Department of Veterans Affairs and US Department of Defense clinical practice guideline. Pain Med. 2018;19(5):928-941.

34. Chou R, Hartung D, Turner J, et al. Comparative Effectiveness Review Number 229: Opioid Treatments for Chronic Pain. AHRQ publication 20-EHC011. Rockville, MD: Agency for Healthcare Research and Quality; April 2020.

Andrew Kolodny, MD is a senior scientist and the medical director of the Opioid Policy Research Collaborative in the Heller School for Social Policy and Management at Brandeis University in Waltham, Massachusetts, and teaches about the opioid crisis at the Columbia University Mailman School of Public Health. He is also the executive director of Physicians for Responsible Opioid Prescribing. 


\section{Citation}

AMA J Ethics. 2020;22(8):E743-750.

DOI

10.1001/amajethics.2020.743.

\section{Conflict of Interest Disclosure}

Dr Kolodny has served, and continues to serve, as an expert witness on behalf of states and counties in litigation against opioid manufacturers and distributors. He is also the executive director of Physicians for Responsible Opioid Prescribing.

The viewpoints expressed in this article are those of the author(s) and do not necessarily reflect the views and policies of the AMA.

Copyright 2020 American Medical Association. All rights reserved. ISSN 2376-6980 